\title{
To Study Structural and Functional Cardiac Changes in Children with Severe Acute Malnutrition
}

\author{
Mukesh Kumar Prajapati1 ${ }^{1}$ Jeetendra Kumar Singh ${ }^{2}$ \\ ${ }^{1}$ Senior Resident, Department of Paediatrics, Shyam Shah Medical College, Rewa, Madhya Pradesh, India. \\ ${ }^{2}$ Assistant Professor, Department of Paediatrics, Shyam Shah Medical College, Rewa, Madhya Pradesh, India.
}

\section{ABSTRACT}

\section{BACKGROUND}

Severe acute malnutrition (SAM) is one of the most important health problems affecting hundreds of millions of children in the world. Malnourished children suffer several alterations in body composition, with loss of heart and skeletal muscle mass, complicated by electrolyte abnormalities and mineral or vitamin deficiencies that could produce cardiac abnormalities. The present study was undertaken to compare cardiac structural and functional parameters in severe malnutrition and age matched control in Indian children. We wanted to assess the structural and functional cardiac changes in children with severe acute malnutrition.

\section{METHODS}

This is a case control study conducted in paediatric cardiology clinic and severe malnutrition treatment unit (SMTU) of department of paediatrics SSMC associated Gandhi Memorial Hospital, Rewa, M. P. 50 SAM children admitted in SMTU and 50 normal children aged 6 months to 60 months were included in the study. Structural and functional cardiac parameters in SAM children (Cases) were compared with those of normal children (Controls) on the basis of Echocardiography. For structural cardiac changes, interventricular septum thickness (IVS), left ventricular internal diameter (LVID), left ventricular posterior wall thickness (LVPW) and left ventricular mass (LVM) were measured. For functional cardiac changes ejection fraction (EF), fractional shortening (FS) and stroke volume (SV) were measured.

\section{RESULTS}

In the present study, all structural parameters viz the 'IVSs' during systole, IVSd during diastole, LVPWs during systole, LVPWd during diastole, and LVM, all parameters were significantly reduced in SAM children as compared to normal children and functional changes in the form of ejection fraction, fractional shortening and stroke volume $(\mathrm{p}<0.0001)$ were also significantly reduced.

\section{CONCLUSIONS}

There was significant reduction in structural (Thickness of IVS, LVPW and LVM) and functional parameters (EF, FS and SV) in SAM children as compared to normal children.

\section{KEY WORDS}

Myocardial Function, Echocardiography, Left Ventricular Mass
Corresponding Author: Dr. Jeetendra Kumar Singh, F-6/4, New Doctor Colony, Rewa-486001, Madhya Pradesh, India. E-mail: dr.jksingh2005@gmail.com

DOI: $10.14260 / \mathrm{jemds} / 2019 / 652$

Financial or Other Competing Interests: None.

How to Cite This Article:

Prajapati MK, Singh JK. To study structural and functional cardiac changes in children with severe acute malnutrition. J. Evolution Med. Dent. Sci. 2019;8(40):3001-3004, DOI: $10.14260 /$ jemds/2019/652

Submission 30-07-2019,

Peer Review 20-09-2019,

Acceptance 27-09-2019,

Published 07-10-2019. 


\section{BACKGROUND}

As per WHO criteria, severe acute malnutrition (SAM) is defined as the state of weight for height below -3SD of the median as per WHO growth standards with severe wasting or nutritional oedema. SAM is one of the most important health problems, involving hundreds of millions of children in the world.[1] According to national family health survey-IV, in India $7.5 \%$ of children below 60 month of age suffer from severe wasting which constitutes around 10 million.[2] In malnutrition there is a decreased body pool of protein with or without fat depletion that is caused by inadequate nutrient intake relative to nutrient demand that is needed to ensure growth and maintenances. Malnutrition affect approximately one third of children worldwide and is frequently seen in less developed countries due to inadequate intake, socioeconomic factors or at times, due to nutrition disasters. [3] Malnourished children suffer several alterations in body composition, with loss of heart and skeletal muscle mass, complicated by electrolyte abnormalities and mineral or Vitamin deficiencies that could produce cardiac abnormalities including hypotension, cardiac arrhythmias, cardiomyopathy, cardiac failure and even sudden death. $[4,5,6,7]$

Keyes et al (1947)[8] were first to focus attention on reduced heart size in semi starvation, after them various studies were done to assess cardiac functions and dimensions in malnourished children. Phornphatkul et al. (1994) ${ }^{[9]}$ reported that children with malnutrition not only have cardiac muscle wasting but also have inherent ventricular dysfunction as result of severe malnutrition that respond to nutritional therapy.

A number of studies are suggestive of a possible association of myocardial injury in SAM based on clinical findings, electrocardiogram (ECG), echocardiographic patterns, \& classical biochemical markers. ${ }^{[10]}$

The present study was undertaken to compare cardiac structural and functional parameters in severe malnutrition and age matched control in Indian children.

\section{METHODS}

This study was conducted in paediatric cardiology clinic of tertiary care hospital in central India over period of 12 months from April 2016 to March 2017. Cases included 50 children with severe acute malnutrition and 50 children without malnutrition were assigned as controls aged between 6 months to 60 months admitted in wards. A structured proforma was filled for every child enrolled in study. A written informed consent was taken from parents of all children.

\section{Inclusion Criteria}

for SAM (WHO Reference)

1. Weight for height/length <- 3SD.

2. Mid upper arm circumference (MUAC) of $<11.5 \mathrm{~cm}$.

3. Bipedal nutritional oedema.

\section{Exclusion Criteria}

1. Children who were born either premature or small for gestational age.
2. Documented cardiac disease (Congenital heart disease, pericarditis, myocarditis cardiomyopathy).

3. Severe anaemia (haemoglobin level $<6 \mathrm{gm} / \mathrm{dl}$ ).

Total 658 children were admitted in SMTU during study period, out of them 169 children were excluded as per exclusion criteria. Prevalence of cardiac changes in severe acute malnourished children is not known so 50 children were selected with SAM and 50 children without SAM.

Sample size was taken based on the conveniences of the study. All enrolled children underwent detailed history, clinical examination, including anthropometry (weight, length/height, mid upper arm circumference), routine investigations including complete blood counts, renal, liver function tests, serum electrolytes and Echocardiography to assess cardiac function.

\section{Study Design}

Case control study.

\section{Echocardiography}

M-mode echocardiography was performed using Philips HD7XE Echo Machine to record following parameters, for structural cardiac changes interventricular septum thickness (IVS), left ventricular internal diameter thickness (LVID), left ventricular posterior wall thickness (LVPW) and left ventricular mass (LVM) were measured during systole and diastole. For functional cardiac changes ejection fraction (EF), fractional shortening (FS) and stroke volume (SV) were measured.

Left ventricular fractional shortening (FS) was calculated using the following formula: FS=EDD-ESD/EDD X 100.

EDD is end diastolic diameter of left ventricle.

ESD is end systolic diameter of left ventricle.

Ejection fraction (EF) measured from the "cubed equation" $\mathrm{EF}=(\mathrm{EDD})^{3}-(\mathrm{ESD})^{3} /(\mathrm{EDD})^{3} \mathrm{X} 100$

Left ventricular mass was calculated as Left ventricular mass $($ gms $)=\left[(\text { LVIDd }+ \text { IVSd }+ \text { LVPWd })^{3}-(\text { LVIDd })^{3}\right] \times 1.04,[11]$

\section{Statistical Method}

Data were entered in Microsoft ${ }^{\circledR}$ Excel spread sheets. The numerical data has been represented as mean $\pm 2 \mathrm{SD}$ for comparison between two groups. All quantitative data were compared by unpaired t-test and qualitative data by chisquare test considered significant if $p$-value $<0.05$.

\section{RESULTS}

In present study out of 50 SAM children $72 \%$ were males and in control group 54\% children were male. The mean age in SAM children was 17 months (16.8 \pm 11.12 months) and in normal children 24 months (23.98 \pm 12.38 months). In our study we found that mean haemoglobin $(9.43 \pm 2.10 \mathrm{gm} \%)$ and calcium $(0.99 \pm 0.18 \mathrm{mmol} / \mathrm{l})$ level in SAM children were significantly lower as compared to mean $\mathrm{Hb}(11.15 \pm 1.26$ gm $\%)$ and calcium $(1.05 \pm 0.10 \mathrm{mmol} / \mathrm{L})$ in normal children $(\mathrm{p}<0.05)$ (Table-1).

Interventricular septal thickness during systole \& diastole, left ventricular posterior wall thickness during systole \& diastole and also left ventricular mass were 
significantly reduced in SAM children as compared to normal children $(\mathrm{P}<0.05)($ table-2).While there was no significant difference in left ventricular internal diameter during systole and diastole in SAM children and normal children $(p>0.05)$ (Table-2). We also observed that functional cardiac changes in form of ejection fraction, Fractional shortening and stroke volume significantly lower in SAM children as compared to normal children (Table-3).

\begin{tabular}{|c|c|c|c|}
\hline Parameters & $\begin{array}{c}\text { SAM Children } \\
(\mathbf{n = 5 0})\end{array}$ & $\begin{array}{c}\text { Normal Children } \\
(\mathbf{n = 5 0 )}\end{array}$ & p-Value \\
\hline Mean Age (Month) & $16.8 \pm 11.12$ & $23.98 \pm 12.38$ & 0.021 \\
\hline Gender(Male/Female) & $36 / 14$ & $27 / 23$ & \\
\hline Mean Haemoglobin (g/dl) & $9.43 \pm 2.10$ & $11.15 \pm 1.26$ & $<0.0001$ \\
\hline Mean Sodium (meq/l) & $138 \pm 4.07$ & $138.37 \pm 3.9$ & $>0.05$ \\
\hline Mean Potassium (meq/l) & $3.87 \pm 0.4$ & $3.93 \pm 0.38$ & $>0.05$ \\
\hline Mean Calcium (mmol/l) & $0.99 \pm 0.18$ & $1.05 \pm 0.10$ & 0.042 \\
\hline \multicolumn{3}{|c|}{ Table 1. Clinical Characteristics and Lab Data in SAM Children } \\
Compared with Normal Children \\
\hline
\end{tabular}

\begin{tabular}{|c|c|c|c|}
\hline Cardiac Parameters & SAM Children & Normal Children & p-Value \\
\hline IVSs (cm) & $0.85 \pm 0.17$ & $1.03 \pm 0.06$ & $<0.0001$ \\
\hline IVSd (cm) & $0.69 \pm 0.13$ & $0.91 \pm 0.05$ & $<0.0001$ \\
\hline LVPWs (cm) & $0.82 \pm 0.17$ & $1.04 \pm 0.20$ & $<0.0001$ \\
\hline LVPWd (cm) & $0.69 \pm 0.14$ & $0.85 \pm 0.21$ & $<0.0001$ \\
\hline LVM (gm) & $35.15 \pm 11.10$ & $55.98 \pm 15.72$ & $<0.0001$ \\
\hline LVIDs (cm) & $1.44 \pm 0.27$ & $1.37 \pm 0.26$ & $>0.05$ \\
\hline LVIDd (cm) & $2.13 \pm 0.40$ & $2.24 \pm 0.40$ & $>0.05$ \\
\hline \multicolumn{4}{|c|}{ Table 2. Structural Cardiac Parameters of SAM Children } \\
\hline
\end{tabular}

IVSs-interventricular septal thickness during systole, IVSd-interventricular septal thickness during diastole, LVPWs-left ventricular posterior wall thickness during systole, LVPWd- left ventricular posterior wall thickness during diastole, LVM- left ventricular mass, LVIDs- left ventricular internal diameter during systole, LVIDd- left ventricular internal diameter during diastole.

\begin{tabular}{|c|c|c|c|}
\hline Cardiac Parameters & SAM Children & Normal Children & p-Value \\
\hline EF (\%) & $63.44 \pm 6.66$ & $71.00 \pm 5.45$ & $<0.0001$ \\
\hline FS (\%) & $33.45 \pm 5.16$ & $38.49 \pm 4.37$ & $<0.0001$ \\
\hline SV(ml/beat) & $10.42 \pm 4.15$ & $15.90 \pm 4.55$ & $<0.0001$ \\
\hline Table 3. Functional Cardiac Parameters of SAM Children Compared \\
with Normal Children \\
\hline
\end{tabular}

EF-ejection fraction, FS-fractional shortening, SV-stroke volume.

\begin{tabular}{|c|c|c|c|c|c|c|c|c|c|c|c|c|}
\hline \multirow[b]{2}{*}{$\mid \begin{array}{l}\dot{0} \\
z \\
\dot{n}\end{array}$} & \multirow{2}{*}{ 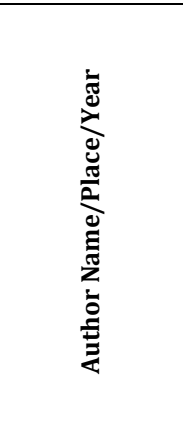 } & \multicolumn{2}{|c|}{ Subjects } & \multirow{2}{*}{\multicolumn{2}{|c|}{ 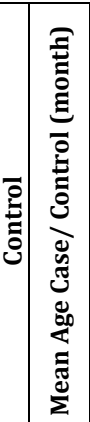 }} & \multicolumn{5}{|c|}{$\begin{array}{l}\text { Structural Cardiac } \\
\text { Parameters }\end{array}$} & \multicolumn{2}{|c|}{$\begin{array}{c}\text { Functional } \\
\text { Cardiac } \\
\text { Parameter } \\
\text { s }\end{array}$} \\
\hline & & 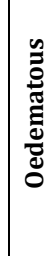 & 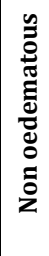 & & & 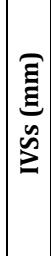 & 点 & 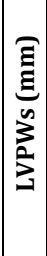 & 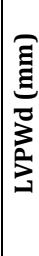 & 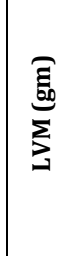 & 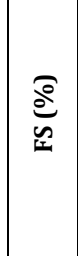 & 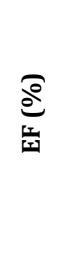 \\
\hline 1 & $\begin{array}{c}\text { Shoukry, } \\
\text { et al./ Newyork/ } \\
1986 \\
\end{array}$ & 17 & & 17 & 15 & & & & & 8.11 & 32 & 71 \\
\hline 2 & $\begin{array}{c}\text { Kothari et } \\
\text { al./India/1991 }\end{array}$ & 10 & 15 & 26 & 30 & & & & & 25.7 & & 62 \\
\hline 3 & $\begin{array}{c}\text { B Ocal et } \\
\text { al/Turkey/2001[5] }\end{array}$ & 11 & 19 & 17 & $9 / 7$ & $\begin{array}{c}5 \pm \\
1\end{array}$ & $4 \pm 1$ & & $\begin{array}{c}3 \pm \\
5\end{array}$ & $\begin{array}{c}14.5 \pm \\
5.2\end{array}$ & $=35.7 \pm$ & $\begin{array}{c}66 \pm \\
6.0\end{array}$ \\
\hline 4 & $\begin{array}{l}\text { Jose' L. Olivares et } \\
\text { al/Spain/2005[4] }\end{array}$ & & 30 & 30 & $\begin{array}{c}28 / 2 \\
9 \\
\end{array}$ & & & & & $\begin{array}{l}55 \pm \\
10.3 \\
\end{array}$ & \begin{tabular}{|l|}
$39 \pm$ \\
2.31 \\
\end{tabular} & $\begin{array}{l}64 \pm \\
3.86 \\
\end{array}$ \\
\hline 5 & $\begin{array}{c}\text { El-Sayed et } \\
\text { al/Egypt/2005 }\end{array}$ & 14 & 16 & 10 & & & & & & & $\begin{array}{l}34 \pm \\
6.73 \\
\end{array}$ & $\begin{array}{l}69 \pm \\
10.4 \\
\end{array}$ \\
\hline
\end{tabular}

\begin{tabular}{|c|c|c|c|c|c|c|c|c|c|c|c|c|}
\hline 6 & $\begin{array}{l}\text { Faddan et } \\
\text { al/Egypt/2010[6] }\end{array}$ & 7 & 38 & 25 & $\begin{array}{c}12 / 1 \\
0\end{array}$ & & & & \begin{tabular}{|l|}
$4 \pm$ \\
0.8
\end{tabular} & \begin{tabular}{|c|}
$18.9 \pm$ \\
7 \\
.5
\end{tabular} & $\begin{array}{l}46 \pm \\
13\end{array}$ & $\begin{array}{c}40.3 \pm \\
9.1\end{array}$ \\
\hline 7 & $\begin{array}{c}\text { Agrawal et } \\
\text { al/Jaipur/ } \\
2016\end{array}$ & 7 & 25 & 32 & $\begin{array}{c}17 / 2 \\
9\end{array}$ & & \begin{tabular}{|c|}
4.76 \\
\pm \\
1.1 \\
\end{tabular} & & \begin{tabular}{|c|}
4.1 \\
\pm \\
0.7 \\
\end{tabular} & \begin{tabular}{|c|}
$18.3 \pm$ \\
7.6
\end{tabular} & $\begin{array}{c}34.4 \pm \\
3.8\end{array}$ & $\begin{array}{c}65.7 \pm \\
5.4\end{array}$ \\
\hline 8 & $\begin{array}{l}\text { Reeta Meena } \\
\text { et al/Udaipur/ } \\
2016^{[12]}\end{array}$ & & 100 & & 20 & \begin{tabular}{|c|}
7.3 \\
\pm \\
1.7
\end{tabular} & $\begin{array}{c}4.8 \pm \\
0.8\end{array}$ & $\begin{array}{c}7.7 \\
\pm \\
1.4 \\
\end{array}$ & \begin{tabular}{|c|}
4.6 \\
\pm \\
0.9 \\
\end{tabular} & & $\begin{array}{c}38.5 \pm \\
7.9\end{array}$ & $\begin{array}{c}70.6 \pm \\
9.5\end{array}$ \\
\hline 9 & Present study/Rewa & & 50 & 50 & $\begin{array}{r}17 / \\
24\end{array}$ & $\begin{array}{c}8.5 \\
\pm \\
1.7\end{array}$ & $\begin{array}{c}6.9 \pm \\
1.3 \\
\end{array}$ & \begin{tabular}{|c|}
8.2 \\
\pm \\
1.7 \\
\end{tabular} & $\begin{array}{c}6.9 \\
\pm \\
1.4 \\
\end{array}$ & $\begin{array}{c}35.1 \pm \\
11.1 \\
\end{array}$ & $\begin{array}{c}33.4 \pm \\
5.16\end{array}$ & $\begin{array}{c}63.4 \pm \\
6.66\end{array}$ \\
\hline
\end{tabular}

\section{DISCUSSION}

Structural cardiac parameters in form of LV interventricular septal thickness during systole and diastole, LV posterior wall thickness during systole and diastole and left ventricular mass were reduced in severe acute malnourished children as compared to normal children. And cardiac function in form of fractional shortening, ejection fraction and stroke volume were lower in SAM children as compared to normal children. But there is no significant difference in Left ventricular internal diameter during systole and diastole in both groups.

Similar result were found in previous study by Nagla Hassan Abu Faddan et al (2010),[6] They reported mean interventricular septal diameter, posterior wall diameter, left ventricular mass to be reduced i $n$ malnourished patients( 45 cases) in comparison to apparently healthy controls (25 controls), Fractional shortening and ejection fraction were also reduced in malnourished patients, while end systolic diameter (ESD)and end diastolic diameter (EED) were not significantly different among both groups,

Shoukry et al (1986),[13] detected that left ventricular mass was significantly reduced in kwashiorkor as compared to healthy children in same age. And they also reported impairment of left ventricular function as evidenced by reduction fractional shortening and ejection fraction in kwashiorkor. Phornphatkul et al. (1994)[14] concluded that the children with primary third-degree malnutrition not only have cardiac wasting, but also inherent ventricular dysfunction as the result of severe malnutrition that responds to nutritional therapy.

Ocal et $\mathrm{al}^{4}(2001),{ }^{[5]}$ found mean LVMass, left ventricular septal diameter and posterior wall thickness were reduced in malnourished children. Jose' L. Olivares, et $\mathrm{al}^{9}(2005)^{[4]}$ found that although LVEDD, LVESD, LVM and LVMI were significantly lower in malnourished children, there were no statistical differences between the left ventricular fractional shortening and left ventricular ejection fraction.

Singh GR et al (1989) ${ }^{[15]}$ reported that left ventricular systolic functions were reduced especially in children with moderate and severe protein energy malnutrition as compared to normal nourished children. Kothari, et al (1992)[16] also found that mean LVM was in severe PEM significantly reduced as compared to normal nutritional status children and significantly reduced cardiac output in severe PEM. Agrawal et al (2016) ${ }^{[17]}$ in they found mean posterior wall thickness, LV mass which is also less in malnourished children as compared to control group. 


\section{CONCLUSIONS}

Structural cardiac changes in the form of interventricular septal thickness, left ventricular posterior wall thickness and left ventricular mass were significantly reduced in SAM children as compared to normal children. The functional cardiac parameters like ejection fraction, fractional shortening and stroke volume were also low in SAM children as compared to normal children. As all children with cardiac diseases and severe anaemia were excluded from study, these structural and functional changes could be attributed to severe malnutrition. The evidence of myocardial dysfunction is an indicator for being cautions in fluid management in such children. Further serial ECHO may guide recovery of structural and functional myocardial changes and also duration of recovery. Till that period, caution has to be observed in fluid management in severe malnutrition.

What is already known?

Structural cardiac changes were observed in malnourished children and functional cardiac changes were more severe in oedematous malnutrition.

What this study adds?

Severe non oedematous malnutrition per se results in structural and functional cardiac changes.

\section{REFERENCES}

[1] Sachdev HP, Kapil U, Vir S. Consensus Statement: national consensus work shop on management of SAM children through medical nutrition therapy. Indian Pediatrics 2010;47(8):661-5.

[2] International Institute for population sciences. National family health survey - 4. Mumbai India: International Institute of Population Science: 2015-2016.

[3] Gray VB, Cossman JS, Powers EL. Stunted growth is associated with physical indicators of malnutrition but not food insecurity among rural school children in Honduras. Nutr Res 2006;26(11):549-55.

[4] Olivares JL, Vazquez M, Rodriguez G, et al. Electrocardiographic and echocardiographic changes in malnourished children. J Am Coll Nutr 2005;24:38-43.

[5] Öcal B, Ünal S, Zorlu P, et al. Echocardiographic evaluation of cardiac functions and left ventricular mass in children with malnutrition. J Paediatr Child Health 2001;37(1):14-7.

[6] Faddan NH, Sayh KI, Shams H, et al. Myocardial dysfunction in malnourished children. Annals of Paediatric Cardiology 2010;3(2):113-8.

[7] Olowonyo MT, Ogunkunle 00, Akinbami FO, et al. The echocardiographic findings in Kwashiorkor. J trop Pediatr 1995;41(2):74-6.

[8] Keys A, Henschel A, Taylor HL. The size and function of human heart at rest in semi starvation and in subsequent rehabilitation. Am J of Physiol 1947;150(1):153-69.

[9] Phornphatkul C, Pongprot Y, Suskind R, et al. Cardiac function in malnourished children. Clin Pediatr (Philadelphia) 1994;33(3):147-54.

[10] Clark B. Nutritional assessment and prevention of protein energy malnutrition. In: Campbell A, McIntoch, eds. Forfar and Arneil's Textbook of Pediatrics. $5^{\text {th }}$ edn. New York, London, Churchill Livingstone Publisher 1998: p. 1186-94

[11] Devereux RB, Reichek N. Echocardiographic determination of left ventricular mass in man. Anatomic validation of the method. Circulation 1977;55(4):613-8.

[12] Meena R, Suman RL, Meena P, Meena SL. Myocardial performance index in severe acute malnutrition children aged 6 months to 5 years. International Journal of Contemporary Paediatrics 2016;3(3):833-6.

[13] Shoukry I, Shoukry AS, Ibrahim MM, et al. Cardiac atrophy and ventricular function in infants with severe protein calorie malnutrition (Kwashiorkor Disease). In: Doyle EE, Engle MA, Gwersony WJ, et al. eds. Pediatric Cardiology. New York: Springer-Verlag 1986: p. 1169-71.

[14] McDonald IJ, Feigenbaum H, Chang S. Analysis of left ventricular wall motion by reflected ultrasound. Application to assessment of myocardial function. Circulation 1972;46(1):14-25.

[15] Singh GR, Malathi KE, Kasliwal RR, et al. An evaluation of cardiac function in malnourished children by noninvasive methods. Indian Paediatrics 1989;26(9):875-81.

[16] Kothari SS, Patel TM, Shetalwad AN, et al. Left ventricular mass and function in children with severe protein energy malnutrition. International Journal of Cardiology 1992;35(1):19-25.

[17] Agrawal P, Gupta VK, Gupta S, et al. A study on myocardial function in children with severe acute malnutrition. Int J Med Sci \& Edu 2016;3(1):152-6. 